\title{
TEMPERAMENTAL DIMENSIONS AMONG YOUNG STUTTERERS AND TYPICALLY DEVELOPING CHILDREN
}

\author{
Zubia Mushtaq, Nazia Mumtaz*, Ghulam Saqulain** \\ Ayub Teaching Hospital, Abbottabad Pakistan, *Shifa Tameer-e-Millat University, Islamabad Pakistan, ${ }^{* *}$ Capital Hospital, Islamabad Pakistan
}

\section{ABSTRACT}

Objective: To compare the temperamental characteristics of children who stutter with those who do not stutter.

Study Design: Comparative cross-sectional study.

Place and Duration of Study: Ayub Medical Complex, Abbottabad, from Jun to Nov 2018.

Methodology: We recruited 120 children of both genders aged 3-8 years. Sample recruited included two groups including 60 children with stuttering (CWS) and 60 children with no stuttering (CWNS), using consecutive sampling. After taking consent, data was gathered using demographic sheet and Children Behavioral Questionnaire (CBQ) from the sample population. Statistical analysis was done using SPSS-21.

Results: The sample included 82 (68.3\% males and 38 (31.7\%) female children. t-test results of children with stuttering and children with no stuttering showed statistically significant difference for effortful control $(p<0.05)$ including dimension of inhibitory control, low intensity pleasure and perceptual sensitivity. However, the values for Surgency Extraversion and Negative affectivity were not statistically significant though results showed higher and lower mean scores respectively for stutterers compared to non-stutterers. However, the dimensions of anger, frustration, discomfort and falling reactivity showed statistically significant difference $(p<0.05)$.

Conclusion: Children with stuttering and children with no stuttering differ in their temperamental characteristics with statistically significant difference for effortful control with lower control in stutterers.

Keywords: Children, Effortful control, Inhibition, Stuttering, Temperament.

How to Cite This Article: Mushtaq Z, Mumtaz N, Saqulain G. Temperamental Dimensions Among Young Stutterers and Typically Developing Children. Pak Armed Forces Med J 2021; 71(Suppl-3): S471-475. Doi: https://doi.org/10.51253/pafmj.v1i1.3758

\footnotetext{
This is an Open Access article distributed under the terms of the Creative Commons Attribution License (https://creativecommons.org/licenses/by-nc/4.0/), which permits unrestricted use, distribution, and reproduction in any medium, provided the original work is properly cited.
}

\section{INTRODUCTION}

Temperament may be defined as individual biological difference that is perhaps relatively stable over time, and in most cases appears in early development of the child. However according to Shiner et al, ${ }^{1}$ the most recent research defines Temperament as: "Early emerging basic dispositions in the domains of activity, affectivity, attention, and self-regulation, and these dispositions are the product of complex interactions among genetic, biological, and environmental factors across time". Temperament characteristics can be studied in the newborn and infants who show different emotions of anger, smile, laughter, distress, and body movements. They also show great unpredictability while responding or reacting to the environment. Temperament and habilitation help the child grow his/her personality, values, attitudes, and coping strategies. These responses along with the regulating mechanisms constitute the child's temperament. Stuttering on the other hand can be defined as disorder in fluency and time patterning of speech that persists overtime, characterized by pauses, repetitions, breaks, spasms etc.,

Correspondence: Dr Ghulam Saqulain, ENT Department, Capital Hospital, PGMI, Sector G-6/2, Islamabad Pakistan and hence affecting intelligibility. ${ }^{2}$

Recent researches indicate connections between temperamental characteristics, emotional processes and stuttering. Empirical findings suggest that preschool children with stuttering (CWS) show differences in emotion and temperament in comparison to children with no stuttering (CWNS) or typically developing children (TDC). . $^{3,4}$ According to Choi et al, temperament interacts with speech language disability in a number of ways including behavioral inhibition. ${ }^{5}$ Thus, Temperament plays a vital role in numerous aspects of speech and language development as well as communication disorders like stuttering. ${ }^{4}$ Different tools are used to measure Temperamental dimensions. Children's Behavior Questionnaire (CBQ), ${ }^{6}$ is among the universally employed questionnaire to access temperament in children and is a detailed, multi-dimensional, reliable and valid tool. A number of empirical studies report temperamental differences between CWS and CWNS/ TDC. Anderson JD in a review article noted that CWS could have more sensitive and vulnerable temperament smaking it difficult for them to recover from stuttering. They may have reduced attention span, difficulty adapting, and may be 
anxious, sensitive and withdrawn, ${ }^{7}$ with low score on dimension of extraversion. ${ }^{8}$

Researchers have proposed that temperamental dimensions can generate impacton stuttering e.g. CWS are neither extraverted nor active, social and open as compared to TDC. ${ }^{9}$ It has also been noted that children with more behavioral inhibition (being one aspect of temperament) results in more stuttering in CWS thus supporting further referential research. ${ }^{10}$ Shiner et al, in their study concluded that the future research on temperament in coming decadeswill pursue sophisticated answers to questions about the nature of temperament and improving quality of life (QOL) of children. ${ }^{1}$ Pertaining to the significance of the matter there being dearth of studies on temperament of CWS of school age, this study was conducted with the aim to examine the relationship between temperament and stuttering. This study will help identify role of temperament in stuttering. The current study is imperative since there is dearth of literature on this important issue.

\section{METHODOLOGY}

This was comparative Cross-Sectional study design usingconsecutive sampling to recruit a study population of 120 children. These including 60 CWS and 60 CWNS/TDC, of either gender, aged 3-8 years, for comparative purposes to access the temperamental characteristics of the two groups. Sample size of 122 was calculated using Open Epi sample size calculator with two-sided confidence level of $95 \%$ and power of $80 \%$. Study conducted at Ayub Medical Complex, Abbottabad, Pakistan from June to November 2018 to assess the relationship among stutterers and nonstutterers. Cases withdelayed language development, dyslexia, and mental retardation, hearing impairment, psychological or neurological problems were excluded.

Study was conducted after obtaining ethics approval from Institutional Research Board of Isra University vide No.1602-MPhil. SLP-002 dated 4th May, 2018. Following consent for inclusion in study, data was gathered using basic demographical sheet and Children Behavior Questionnaire (CBQ). Temperament of the children was evaluated by making use of the English version of the CBQ 11 and responses were obtained from the parents (In 102 (85\%) cases both parents were present and in $18(15 \%)$ cases mothers responded). The $C B Q$ is a parent-report questionnaire consisting of 94 items categorized into 15 dimensions of temperament and subsequently grouped into 3 Factors namely Negative effect, Surgency and Effortful control. To complete the questionnaire, parents rated each item on a 7-point Linkert scale (1=extremely untrue of your child, 2=quite untrue of your child, $3=$ slightly untrue of your child, $4=$ neither true nor false of your child, $5=$ slightly true of your child, $6=$ quite true of your child, and $7=$ extremely true of your child). All questions of $\mathrm{CBQ}$ questionnaire included in the current study were completed by the children's parents.

Statistical Analysis of the data was done using SPSS-21. Based on the CBQ 15 dimensions structure three normalized composite factor scores were computed for each participant using the regression method. Independent-Sample t-test was performed on the composite temperament factor scores of the 60 CWS and 60 CWNS of the current study to examine whether significant differences existed between the participant groups on the 3 composite factors. Possible differences between CWNS and CWS on the 15 individual temperament scales were also investigated using an Independent-sample t-test, with participant group as the independent variable; and composite factor scores and temperament scales as the dependent variables. The dependent variables were tested simultaneously in order to control for Type 1 errors. The results obtained were compared with the national and international literature and deductions observed were then discussed.

\section{RESULTS}

Our study population comprised of 120 children with age range of 3-8 years with $36(30 \%)$ in 3-5 years and $84(70 \%)$ in 6-8 years age group. Of these 82 $(68.3 \%)$ were males and $38(31.7 \%)$ females (Table-I).

\begin{tabular}{|c|c|}
\hline Demographics & n (\%) \\
\hline \multicolumn{2}{|l|}{ Age Group (Years) } \\
\hline $3-5$ & $36(30)$ \\
\hline $6-8$ & $84(70)$ \\
\hline \multicolumn{2}{|l|}{ Gender } \\
\hline Male & $82(68.3)$ \\
\hline Female & $38(31.7)$ \\
\hline \multicolumn{2}{|l|}{ Mother's Education } \\
\hline Illiterate & $17(14.2)$ \\
\hline Graduation & $78(65)$ \\
\hline Masters & $25(20.8)$ \\
\hline \multicolumn{2}{|l|}{ Father's Education } \\
\hline Illiterate & $2(1.7)$ \\
\hline Graduation & $76(63.3)$ \\
\hline Masters & $42(35)$ \\
\hline \multicolumn{2}{|l|}{ Father's Occupation } \\
\hline Government employee & $56(46.7)$ \\
\hline Self employed & $64(53.3)$ \\
\hline Birth Order & $42(35)$ \\
\hline Youngest & $54(45)$ \\
\hline Middle Eldest & $21(17.5)$ \\
\hline
\end{tabular}


Among the parents, fathers were mostly educated up to graduation and self-employed while mothers are mostly less educated than Graduation and are housewives.

Figure shows graphical representation of the mean scores for the Dimensions of SBQ questionaire, showing a big difference between CWS and CWNS for Effortful control.

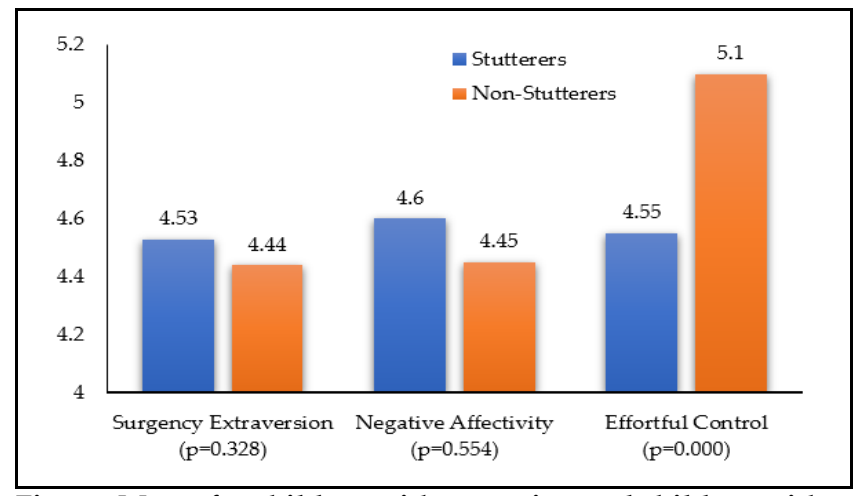

Figure: Meansfor children with stuttering and children with no stuttering on Dimensions of Extraversion, Negative Affectivity and Effortful Control $(n=120)$.
Table-II, shows the descriptive statistics and t-test result of the dimensions of SBQ questionnaire for both CWS and CWNS, showing statistically significant difference between the two groups for Effortful Control $(\mathrm{t}=-2.03, p=0.001, \mathrm{~d}=-0.399)$ with stutters showing less mean score of Effortful Control factor with small effect size. Of the Dimensions of Effortful Control factor, also differ for the two groups and was statistically significant $(p=0.001)$ for Inhibitory Control and Low intensity pleasure.

For the Factors of Extraversion and Negative Affectivity, no statistically significant difference was noted for both CWS and CWNS groups. However, in the Negative Affectivity factor, statistically significant difference was noted with More Anger Frustration $(p=0.004)$ and Discomfort $(p=0.012)$ and Less Falling Reactivity in the CWS group.

Alpha coefficient for CBQ is .70 (Table-III). Also the range of all the scales and the subscales lie within the potential ranges and the value of skewness lies within the acceptable ranges fulfilling the assumptions of normality, hence the above parametric tests were applied for the analysis of the data.

Table-II: Descriptive statistics and t-test result for children with stuttering and children with no stuttering on dimensions of extraversion, negative affectivity and effortful control $(n=120)$.

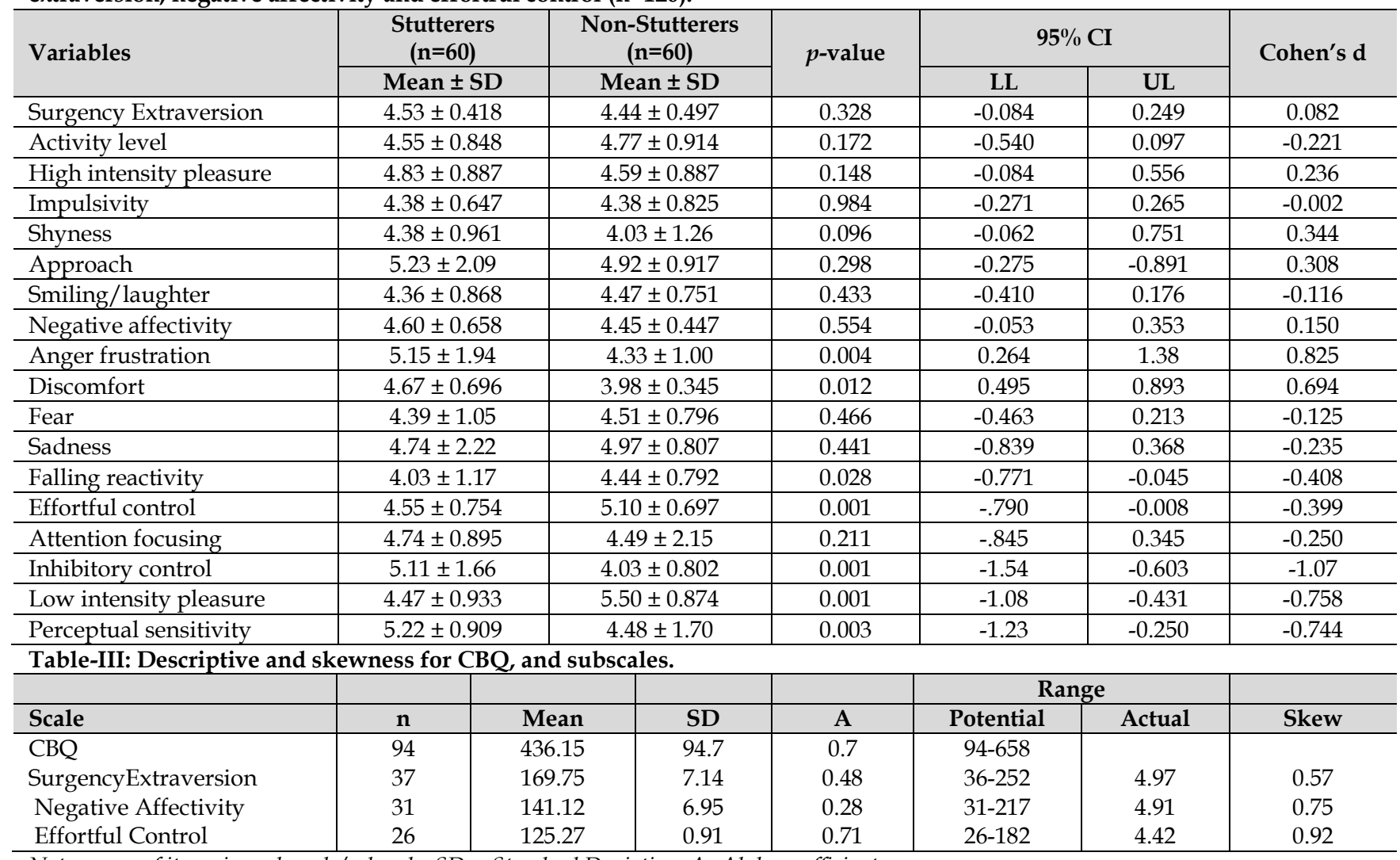

Note. $n=$ no of items in each scale/subscale, $S D=$ Standard Deviation, A=Alpha coefficient 


\section{DISCUSSION}

Temperament may act as a contributing factor to developmental stuttering, with some empirical evidence indicating that preschool age children who stutter (CWS) show differences in temperament and emotion compared with those children who donot stutter (CWNS). ${ }^{12}$

In the current study there was statistically significant difference between CWS and CWNS overall for the Effortful control factor $(p<0.05)$ as well as its dimensions of Inhibitory control, low intensity pleasure and perceptual sensitivity. However, the Surgency Extraversion factor and its dimensions did not reveal any statistically significant difference between the two groups. Also, the Negative affectivity factor did not reveal any statistically significant difference between the two groups, however its dimensions including Anger Frustration, Discomfort and Falling Reactivity showed statistically significant difference between CWS and CWNS.

Similarly, Eggers et al, in their research compared three groups to investigate temperament as regards Surgency Extraversion, Negative Affect and Effortful Control for children using CBQ for stuttering, voice disorder and typically developed children, and found differences in mean scores. ${ }^{13}$ Also, Eggers et al, in another study, in which they continued their examination on temperament of CWS and CWNS, found higher scores on Anger/Frustration, Approach, and Motor Activation while significantly lower score on Inhibitory control and attentional shifting. ${ }^{14}$ However, we noted higher scores for Anger Frustration and Inhibitory control for CWS group which was statistically $(p<0.05)$. In contrast Hollister et al ${ }^{15}$ found CWS to have significantly low effortful control with poor performance in adaptive functioning in CWS compared to CWNS. ${ }^{15}$ Choi et al, in their study noted that children with more behavioral inhibition, being one aspect of temperament, results in more stuttering in CWS. ${ }^{10}$

In a study by Eggers et al, in which questionnaire based assessment of behaviour of children with and without stuttering reflected in computer based Attention Network Test and noted that CWS had significantly low ability of orienting network in comparison to those without stuttering. ${ }^{16}$ While in another study Anderson et al, ${ }^{17}$ using Behavioral style questionnaire (BSQ), noted that CWS, more commonly showed temperamental with less distractibility, they were more non adaptable to change and showed irregular biologi- cal functions, with such characteristics acting to maintain and exacerbate stammering. ${ }^{17}$

In contrast to these studies, Johnson and Karrass, ${ }^{18}$ reported that no significant difference exist between temperament of CWS and CWNS as well as their parents.

Schwenk et al, in their study noted that CWS react more to specific environmental change, are more vigilant but less adaptive to environmental changes, hence face difficulties to establish normal speech fluency. ${ }^{19}$

Therapeutic approaches to strengthen the skills involved in effortful control, have the potential to reduce the effect of stuttering on CWS. ${ }^{20}$

\section{CONCLUSIONS}

We conclude that CWS and CWNS differ in their temperamental characteristics with statistically significant difference for effortful control factor with lower control in stammerers.

\section{Conflict of Interest: None.}

\section{Authors' Contribution}

ZM: Data collection, analysis \& interpretation, NM: Conception of work \& critical review, GS: Manuscript writing and literature review.

\section{REFERENCES}

1. Shiner RL, Buss KA, MeClowry SG. What Is Temperament Now. Assessing Progress in Temperament Research on the TwentyFifth Anniversary of Goldsmith et al. (1987). Child Develop Perspect 2012; 6(4): 436-444.

2. Perez HR, Stoeckle JH. Stuttering Clinical and research update. Can Fam Phys 2016; 62(6): 479-484.

3. Jones RM, Conture EG, Walden TA. Emotional reactivity and regulation associated with fluent and stuttered utterances of preschool-age children who stutter. J Communicat Disord 2014; 48(2): 38-51.

4. Jones R, Choi D, Conture E, Walden T. Temperament, Emotion and Childhood Stuttering. Semin Speech Lang 2014; 35(2): 114131.

5. Choi D, Conture EG, Walden TA, Lambert WE, Tumanova V. Behavioral inhibition and childhood stuttering. J Fluency Disord 2013; 38(2): 171-183.

6. Rothbart MK, Ahadi SA, Hershey KL, Fisher P. Investigations of temperament at three to seven years: the Children's Behavior Questionnaire. Child Dev 2001; 72(5): 1394-408.

7. Anderson JD, Pellowshi MW, Conture EG, Kelly EM. Temperamental Characteristics of Young Children Who Stutter. J Speech Lang Hear Res 2003; 46(5): 1221-1233.

8. Janez J, Jerneja NB. The Temperamental Characteristic of Extraversion in Slovenian Preschool Children Who Stutter. Logoped 2017; 7(1): 6-12.

9. The Temperamental Characteristic of Extraversion in Slovenian Preschool Children Who Stutter. Logoped 2017; 7(1): 6-12. 


\section{Temperamental Dimensions}

10. Hoi D, Conture EG, Walden TA, Lambert WE, Tumanova V. Behavioral inhibition and childhood stuttering. J Fluency Disord 2013; 38(2): 171-183.

11. Rothbart MK, Ahadi SA, Hershey KL, Fisher P. Investigations of temperament at three to seven years: the Children's Behavior Questionnaire. Child Dev 2001; 72(5): 1394-408.

12. Jones R, Choi D, Conture E, Walden T. Temperament, emotion, and childhood stuttering. semin speech Lang 2014; 35(2): 114-31.

13. Eggers K, De Nil LF, Van den Bergh BR. Factorial temperament structure in stuttering, voice disordered, and typically developing children. J Speech Lang Hear Res 2009; 52(6): 1610-1622.

14. Eggers K, De Nil LF, Van den Bergh BRH. Temperament dimensions in stuttering and typically developing children. J Fluen Disord 2010; 35(4): 355-372
15. Hollister JE. "Effortful control and adaptive functioning in school-age children who stutter." PhD (Doctor of Philosophy) thesis, University of Iowa, 2015.

16. Eggers K, De Nil LF. The efficiency of attentional networks in children who stutter. J Speech Lang Hear Res 2012; 55(3): 946-959

17. Anderson JD, Pellowski MW, Conture EG, Kelly EM. Temperamental characteristics of young children who stutter. J Speech Lang Hear Res 2003; 46(5): 1221-1233.

18. Johnson KN, Karrass J. Preliminary Investigation of the Relationship between the Temperament of Young Children Who Stutter and the Temperament of Their Parents. J CommunDisord Deaf Stud Hearing Aids 2017; 5(2): 176-179.

19. Schwenk KA, Conture EG, Walden TA. Reaction to background stimulation of preschool children who do and do not stutter. J Commun Disord 2007; 40(2): 129-141. 